\title{
openheart Impact of chronic obstructive pulmonary disease on morbidity and mortality after myocardial infarction
}

\author{
Pontus Andell, ${ }^{1}$ Sasha Koul, ${ }^{1}$ Andreas Martinsson, ${ }^{1}$ Johan Sundström, ${ }^{2}$ \\ Tomas Jernberg, ${ }^{3} \mathrm{~J}$ Gustav Smith, ${ }^{1}$ Stefan James, ${ }^{2}$ Bertil Lindahl, ${ }^{2}$ David Erlinge ${ }^{1}$
}

To cite: Andell P, Koul S, Martinsson A, et al. Impact of chronic obstructive pulmonary disease on morbidity and mortality after myocardial infarction. Open Heart 2014;1:e000002. doi:10.1136/openhrt-2013000002

- Additional material is published online only. To view please visit the journal online (http://dx.doi.org/10. 1136/openhrt-2013-000002).

Received 6 November 2013 Revised 26 November 2013 Accepted 27 November 2013

\section{${ }^{1}$ Department of Cardiology,} Lund University, Lund, Sweden

${ }^{2}$ Department of Medical Sciences and Cardiology, Uppsala Clinical Research Center, Uppsala University, Uppsala, Sweden

${ }^{3}$ Department of Medicine,

Karolinska Institute,

Stockholm, Sweden

Correspondence to Dr David Erlinge; david.erlinge@med.lu.se

\section{ABSTRACT}

Aim: To gain a better understanding of the impact of chronic obstructive pulmonary disease (COPD) on long-term mortality in patients with myocardial infarction (MI) and identify areas where the clinical care for these patients may be improved.

Methods: Patients hospitalised for MI between 2005 and 2010 were identified from the nationwide Swedish SWEDEHEART registry. Patients with MI and a prior COPD hospital discharge diagnosis were compared to patients with MI without a prior COPD hospital discharge diagnosis for the primary endpoint of allcause mortality at 1 year after MI. Secondary endpoints included rates of reinfarction, new-onset stroke, newonset bleeding and new-onset heart failure at 1 year.

Results: A total of $81191 \mathrm{Ml}$ patients were included, of which 4867 (6\%) had a COPD hospital discharge diagnosis at baseline. Patients with COPD showed a significantly higher unadjusted 1-year mortality (24.6 vs $13.8 \%$ ) as well as a higher rate of reinfarction, new-onset bleeding and new-onset heart failure post-MI. After adjustment for potential confounders, including comorbidities and treatment, the patients with COPD still showed a significantly higher 1-year mortality (HR 1.14, $95 \% \mathrm{Cl} 1.07$ to 1.21 ) as well as a higher rate of newonset heart failure ( $\mathrm{HR} 1.35,95 \% \mathrm{Cl} 1.24$ to 1.47 ), whereas no significant association between COPD and myocardial reinfarction or new-onset bleeding remained.

Conclusions: In this nationwide contemporary study, patients with COPD frequently had an atypical presentation, less often underwent revascularisation and less often received guideline-recommended secondary preventive medications of established benefit. Prior COPD was associated with a higher 1-year mortality and a higher risk of subsequent new-onset heart failure after MI. The association seems to be mainly explained by differences in background characteristics, comorbidities and treatment, although a minor part might be explained by COPD in itself. Improved in-hospital MI treatment and post-Ml secondary prevention according to the guidelines may lower the mortality in this high-risk population.

\section{INTRODUCTION}

Chronic obstructive pulmonary disease (COPD) is currently the fourth leading cause of death worldwide but is expected to

\section{KEY MESSAGES}

Patients with COPD have a high risk of death when suffering from a myocardial infarction.

- The increased risk of death seems to partly be based on comorbidities and undertreatment post-MI.

- By reducing the undertreatment with guideline recommended secondary prevention, their prognosis may be improved.

be the third leading cause in $2030^{1}$ in parallel with an expected global increase in tobacco smoking. ${ }^{2}$ The prevalence of COPD varies between countries and age groups but is estimated to be $9-10 \%$ in adults over 40 years of age. ${ }^{3}$ COPD is an underdiagnosed $^{45}$ and undertreated ${ }^{6}$ disease with as little as only one-fifth of patients aged over 40 years being diagnosed and treated in a primary care setting. ${ }^{7}$

COPD and ischaemic heart disease share common risk factors such as high age and smoking $^{8}$ and a high portion of morbidity and mortality in patients with COPD is attributable to cardiovascular disease. ${ }^{9-11}$ Patients with mild COPD seem to have a higher risk of dying from cardiovascular causes than from respiratory insufficiency. ${ }^{12}$ Reduced lung function, independent of smoking, has been shown to correlate with a higher risk of cardiovascular death ${ }^{10} 13$ and ventricular arrhythmia. ${ }^{14}$ A reduced forced expiratory volume in $1 \mathrm{~s}$ (FEV1) has been implicated as a prognostic marker for all-cause and cardiovascular mortality. ${ }^{15}{ }^{16}$ Chronic inflammation of the lungs is thought to result in systemic inflammation, ${ }^{17}$ measured by increased plasma levels of inflammation markers such as $\mathrm{C}$ reactive protein (CRP). ${ }^{18}$ This could possibly aggravate atherosclerosis, induce arterial stiffness ${ }^{19}$ and contribute to an increased risk of cardiovascular disease. 
When suffering from a myocardial infarction (MI), patients with COPD often have comorbidities and commonly present with atypical symptoms, such as dyspnoea, which may result in diagnostic difficulties and delayed treatment leading to a worse prognosis. ${ }^{20}$ Furthermore, they are less likely to receive reperfusion therapy during hospitalisation $^{21}$ and other MI therapies of proven benefit. $^{22}$

The aim of the present study was to characterise the population with MI with a concurrent COPD diagnosis and investigate the prognostic impact of COPD when suffering from an MI, in a contemporary patient population with widespread use of percutaneous coronary intervention (PCI) and dual antiplatelet inhibition.

\section{MATERIALS AND METHODS Study sample}

Consecutive patients with MI admitted to Swedish coronary care units and entered in the nationwide Swedish Web-system for Enhancement and Development of Evidence-based care in Heart disease Evaluated According to Recommended Therapies (SWEDEHEART) ${ }^{23}$ registry between 2005 and 2010 were available for analyses. The study population consisted of a total of 81191 patients with MI, including ST elevation myocardial infarction (STEMI) and non-STEMI. Of these patients, 4867 (6\%) had a previous COPD hospital discharge diagnosis while 76324 did not. The COPD diagnoses were based on International Classification of Diseases (ICD) codes that can be found in online supplementary table S1.

The SWEDEHEART registry enrols consecutive patients admitted to a coronary care unit because of symptoms suggestive of an acute coronary syndrome. On admission, patients receive written information about SWEDEHEART and other quality-of-care registries; patients are permitted to deny participation in the registry, although few of them exercise this right. According to Swedish law, written consent is not required because quality control is an inherent element of hospital healthcare. Research based on the registry is approved by an institutional ethics committee and all personal identifiers are removed from the SWEDEHEART data file when used for research purposes. Information is collected prospectively regarding baseline characteristics such as age and smoking status as well as ECG findings, examinations, interventions, in-hospital complications, discharge medication and diagnoses. ${ }^{23}$ Information on time of death was obtained from the Swedish National Cause of Death Registry. Information regarding medical history, including previous COPD diagnoses, and re-admissions for reinfarction, stroke or bleeding was obtained from the Swedish National Patient Registry, ${ }^{24}$ which includes diagnoses for all patients hospitalised in Sweden from 1987 and forward. Since 2001, the specialised outpatient care is also included. The validity of COPD diagnoses in the Swedish National Patient
Registry has recently been reported to be good, with a diagnosis likely to be misclassified in less than $10 \%{ }^{25}$

\section{Endpoints}

The primary analysis tested the relationship between a prior COPD hospital discharge diagnosis and the primary endpoint of all-cause mortality during 1 year of follow-up after the initial coronary care unit hospitalisation. Secondary endpoints included 1-year re-admission for reinfarction, defined as a new hospitalisation with an MI diagnosis, new-onset admission for stroke, new-onset bleeding and new-onset heart failure. The corresponding ICD codes that the secondary endpoints are based on can be found in online supplementary table S1.

\section{Statistical analyses}

Rates of predefined endpoints in patients with and without a prior COPD hospital discharge diagnosis were calculated with the Kaplan-Meier estimator. Univariate and multivariate HRs were estimated using the Cox proportional hazards models. Covariates were tested for proportionality by visual inspection. Adjustments for potential confounders were performed stepwise in two models, the first including age, sex, smoking status and comorbidities (previous MI, previous stroke, heart failure, renal failure, hypertension, diabetes, peripheral artery disease, cancer and previous bleeding). The second model also included treatments during hospitalisation and at discharge (heparin, fondaparinux, dalteparin, enoxaparin, GPIIbIIIa-inhibitors, $\beta$-blockers, balloon angioplasty, coronary stenting, as well as discharge medications including ACE inhibitors, angiotensin II receptor blockers, aspirin, clopidogrel, prasugrel, $\beta$-blockers, calcium channel blockers, digoxin, diuretics, statins, nitrates and warfarin). The selection of covariates included in these models was performed with the use of a direct acyclical graph ${ }^{26}$ via a web-based tool (http://www. dagitty.net), as illustrated in online supplementary figure S1. Differences between continuous variables were evaluated using the Student $\mathrm{t}$ test. Differences between categorical variables were analysed with the Pearson $\chi^{2}$ test. All tests were two-sided with a $\mathrm{p}$ value for significance $<0.05$. All analyses were performed in SPSS (SPSS V.20, IBM SPSS statistics).

\section{RESULTS \\ Patient characteristics}

Baseline characteristics for patients with MI and without COPD are outlined in table 1. Many variables differ between the two groups. The mean age was 5 years higher in patients with COPD as well as a threefold higher prevalence of prior heart failure. Furthermore, there was a more than twice as high proportion of renal failure, peripheral artery disease and cancer in patients with COPD. Patients with COPD were also more likely to have suffered from previous MI and stroke as well as being treated with more cardiovascular medications 
Table 1 Baseline characteristics of 81191 consecutive patients with MI with and without COPD in Sweden between 2005 and 2010

\begin{tabular}{|c|c|c|c|}
\hline & Non-COPD & COPD & p Value \\
\hline Number of patients & $76324(94.0)$ & $4867(6.0)$ & \\
\hline Age & $70 \pm 13$ & $75 \pm 9$ & $<0.001$ \\
\hline Female gender & 27466 (36.0) & $2239(46.0)$ & $<0.001$ \\
\hline Body mass index $(n=55516)$ & $26.7 \pm 4.7$ & $25.4 \pm 5.4$ & $<0.001$ \\
\hline Smoking status $(\mathrm{n}=80879)$ & & & $<0.001$ \\
\hline Current smoker & $16522(21.7)$ & 1596 (32.9) & \\
\hline Ex-smoker & $20791(27.3)$ & $2222(45.9)$ & \\
\hline Never smoked & 31850 (41.9) & $681(14.1)$ & \\
\hline Unknown & $6872(9.0)$ & $345(7.1)$ & \\
\hline \multicolumn{4}{|l|}{ Comorbidities } \\
\hline Previous MI & $5990(7.8)$ & $665(13.7)$ & $<0.001$ \\
\hline Previous stroke & $6904(9.0)$ & 650 (13.4) & $<0.001$ \\
\hline Heart failure & $4836(6.3)$ & $983(20.2)$ & $<0.001$ \\
\hline Renal failure & $1478(1.9)$ & $231(4.7)$ & $<0.001$ \\
\hline Hypertension & $14848(19.5)$ & 1537 (31.6) & $<0.001$ \\
\hline Diabetes & $14613(19.1)$ & $999(20.5)$ & 0.018 \\
\hline Peripheral artery disease & $3121(4.1)$ & $498(10.2)$ & $<0.001$ \\
\hline Cancer & $1638(2.1)$ & $258(5.3)$ & $<0.001$ \\
\hline Previous bleeding & $3541(4.6)$ & $428(8.8)$ & $<0.001$ \\
\hline Prior CABG & 2625 (3.4) & $208(4.3)$ & 0.002 \\
\hline Prior $\mathrm{PCl}$ & $1548(2.0)$ & $127(2.6)$ & 0.006 \\
\hline \multicolumn{4}{|l|}{ Prior medication before $\mathrm{MI}$} \\
\hline ACE inhibitor & $12216(16.0)$ & $967(19.9)$ & $<0.001$ \\
\hline Angiotensin II receptor blocker & 7894 (10.5) & $580(12.1)$ & $<0.001$ \\
\hline Aspirin & 23023 (30.2) & 1913 (39.3) & $<0.001$ \\
\hline Clopidogrel & $2603(3.4)$ & $217(4.5)$ & $<0.001$ \\
\hline$\beta$-blocker & 23315 (30.6) & $1544(31.7)$ & 0.161 \\
\hline Calcium channel blocker & 11615 (15.2) & $878(18.0)$ & $<0.001$ \\
\hline Digitalis & $1918(2.5)$ & $290(6.0)$ & $<0.001$ \\
\hline Diuretic & $17170(22.5)$ & 1910 (39.2) & $<0.001$ \\
\hline Statin & $14452(18.9)$ & 1069 (22.0) & $<0.001$ \\
\hline Nitrate & 6331 (8.3) & $630(12.9)$ & $<0.001$ \\
\hline Warfarin & 2816 (3.7) & $275(5.7)$ & $<0.001$ \\
\hline
\end{tabular}

than the patients with non-COPD at baseline, with the exception of $\beta$-blockers.

\section{Clinical presentation, laboratory findings and ECG changes}

The pattern of symptoms differed between the two groups, as shown in table 2. Patients in the COPD group presented more frequently with dyspnoea and less frequently with chest pain as the main presenting symptom compared to patients without COPD. For the patients with COPD, the mean heart rate was higher, while the lab findings revealed lower mean total cholesterol and low-density lipoprotein levels with a higher mean CRP value. More often, the presenting ECG showed atrial fibrillation or flutter in the COPD group and the QRS complex revealed higher percentages of left bundle branch block and right bundle branch block. In contrast, ST elevation was more frequent in the non-COPD group.
Treatments, angiographic findings, complications during hospitalisation and discharge medications

The in-hospital characteristics for patients with MI with and without COPD are outlined in table 3. Invasive investigation and treatments in the form of coronary angiography, balloon angioplasty and stenting were less frequent among patients with COPD while the rate of coronary arterial bypass graft surgery did not differ. The indications for PCI differed between the groups, with STEMI being more prevalent among patients in the non-COPD group while the extent of coronary disease was similar.

Continuous positive airway pressure usage was more common for the COPD group as well as a bleeding requiring transfusion and/or surgery. Patients in the COPD group were also more likely to be discharged with atrial flutter or atrial fibrillation as well as with a lower left ventricular ejection fraction.

Patients with COPD were discharged with fewer medications that have been proven to reduce mortality such as 
Table 2 Characteristics at presentation for 81191 consecutive patients with MI with and without COPD in Sweden between 2005 and 2010

\begin{tabular}{|c|c|c|c|}
\hline & Non-COPD & COPD & p Value \\
\hline Number of patients & 76324 (94.0) & $4867(6.0)$ & \\
\hline Presenting symptoms & & & $<0.001$ \\
\hline Chest pain & 63143 (82.9) & $3191(65.6)$ & \\
\hline Dyspnoea & $5429(7.1)$ & $1092(22.5)$ & \\
\hline Cardiac arrest & $836(1.1)$ & $45(0.9)$ & \\
\hline Other & $6343(8.3)$ & $505(10.4)$ & \\
\hline \multicolumn{4}{|l|}{ Delays from symptom onset } \\
\hline Symptom onset to $\mathrm{ER}<12 \mathrm{~h}$ & 41897 (88.7) & 2461 (87.6) & 0.092 \\
\hline Symptom onset to ICCU $<12 \mathrm{~h}$ & $60084(87.4)$ & $3508(84.0)$ & $<0.001$ \\
\hline Symptom onset to $\mathrm{PCl}<12 \mathrm{~h}$ & 17623 (91.9) & $690(91.1)$ & 0.488 \\
\hline \multicolumn{4}{|l|}{ Clinical findings } \\
\hline Pulmonary oedema & $1542(2.1)$ & $140(3.0)$ & $<0.001$ \\
\hline Heart rate & $80 \pm 23$ & $90 \pm 25$ & $<0.001$ \\
\hline Systolic blood pressure & $147 \pm 30$ & $141 \pm 30$ & $<0.001$ \\
\hline Diastolic blood pressure & $84 \pm 17$ & $80 \pm 18$ & $<0.001$ \\
\hline \multicolumn{4}{|l|}{ Lab findings } \\
\hline Total cholesterol & $5.1 \pm 1.2$ & $4.8 \pm 1.2$ & $<0.001$ \\
\hline LDL & $3.1 \pm 1.1$ & $2.8 \pm 1.0$ & $<0.001$ \\
\hline $\mathrm{HDL}$ & $1.2 \pm 0.4$ & $1.3 \pm 0.5$ & $<0.001$ \\
\hline Creatinine & $95 \pm 57$ & $100 \pm 60$ & 0.001 \\
\hline CRP & $25 \pm 50$ & $38 \pm 60$ & $<0.001$ \\
\hline $\mathrm{Hb}$ & $138 \pm 18$ & $134 \pm 18$ & $<0.001$ \\
\hline \multicolumn{4}{|l|}{ Presenting ECG } \\
\hline Rhythm & & & $<0.001$ \\
\hline Sinus & $66131(86.7)$ & 3958 (81.4) & \\
\hline Atrial fibrillation/flutter & $7686(10.1)$ & $706(14.5)$ & \\
\hline QRS & & & $<0.001$ \\
\hline Normal & $47474(62.7)$ & $2711(56.1)$ & \\
\hline LBBB & $4329(5.7)$ & $397(8.2)$ & \\
\hline RBBB & $3231(4.3)$ & $300(6.2)$ & \\
\hline ST-T segment & & & $<0.001$ \\
\hline Normal & 14595 (19.2) & $941(19.4)$ & \\
\hline ST elevation & $27012(35.5)$ & $1294(26.7)$ & \\
\hline ST depression & 16717 (22.0) & $1205(24.8)$ & \\
\hline Abnormal $\mathrm{T}$ wave & $7681(10.1)$ & $528(10.9)$ & \\
\hline Other & $9056(11.9)$ & 791 (16.3) & \\
\hline
\end{tabular}

aspirin and other platelet inhibitors as well as $\beta$-blockers, statins and ACE inhibitors but more of angiotensin receptor blockers. In contrast, patients in the COPD group were more often discharged with calcium channel blockers, digoxin, diuretics, nitrates and warfarin.

\section{Outcomes}

The crude 1-year mortality was significantly higher in the COPD group compared to the non-COPD group, $24.6 \%$ vs $13.8 \%$ (HR $1.86,95 \%$ CI 1.76 to 1.98 ), as shown in figure 1 and table 4 . After adjusting for differences in baseline characteristics, the mortality remained higher in the COPD group but the HR was significantly lowered (HR 1.32, 95\% CI 1.24 to 1.40 ). After additional adjustment for treatments during hospitalisation and discharge medications, the difference in mortality was further decreased but remained statistically significant (HR $1.14,95 \%$ CI 1.07 to 1.21 ).

The results of the secondary endpoint analyses are shown in table 4. Patients with COPD had a higher rate of reinfarction $16.6 \%$ vs $14.2 \%$ (HR $1.17,95 \%$ CI 1.09 to 1.26), new-onset bleeding $4.1 \%$ vs $2.8 \%$ (HR $1.45,95 \%$ CI 1.25 to 1.69 ) and new-onset heart failure $17.2 \%$ vs $9.7 \%$ (HR $1.84,95 \%$ CI 1.70 to 1.99 ) compared to the non-COPD group in univariate analyses, while there was no difference in the rate of new-onset strokes. However, after adjusting for differences in baseline characteristics, treatment during hospitalisation and discharge medications, no differences in reinfarction rates or new-onset bleeding rates were noted. In contrast, the rate of newonset heart failure remained higher for patients with COPD (HR 1.35, 95\% CI 1.24 to 1.47 ). 
Table 3 In-hospital characteristics of 81191 consecutive patients with MI with and without COPD in Sweden between 2005 and 2010

\begin{tabular}{|c|c|c|c|}
\hline & Non-COPD & COPD & p Value \\
\hline Number of patients & 76324 (94.0) & $4867(6.0)$ & \\
\hline Prehospital thrombolysis & $946(1.4)$ & $34(0.8)$ & 0.007 \\
\hline Anticoagulant therapy & & & $<0.001$ \\
\hline Heparin & $5413(7.1)$ & $198(4.1)$ & \\
\hline Dalteparin/enoxaparin & 34266 (44.9) & $2311(47.5)$ & \\
\hline Fondaparinux & $15705(20.6)$ & $1147(23.6)$ & \\
\hline GPIIBIIIA-inhibition & & & $<0.001$ \\
\hline Abciximab & $12342(16.2)$ & $434(8.9)$ & \\
\hline Tirofiban & $1464(1.9)$ & $48(1.0)$ & \\
\hline Eptifibatide & $4078(5.3)$ & $145(3.0)$ & \\
\hline$\beta$-blocker & & & $<0.001$ \\
\hline Intravenous & $17746(23.3)$ & $908(18.7)$ & \\
\hline Oral & 35500 (46.5) & 2072 (42.6) & \\
\hline Coronary angiography & $55330(72.5)$ & $2697(55.4)$ & $<0.001$ \\
\hline Indication for angiography & & & $<0.001$ \\
\hline Unstable angina/NSTEMI & $30015(54.2)$ & $1610(59.9)$ & \\
\hline STEMI & 21136 (38.2) & $883(32.9)$ & \\
\hline Other & $4251(7.6)$ & $194(7.2)$ & \\
\hline Angiographic findings & & & $<0.001$ \\
\hline Normal/atheromatosis & $760(1.7)$ & $47(2.4)$ & \\
\hline 1-vessel, no left main disease & 20788 (47.3) & $860(43.8)$ & \\
\hline 2-vessel, no left main disease & $13038(29.7)$ & $575(29.3)$ & \\
\hline 3-vessel, no left main disease & 7534 (17.1) & $367(18.7)$ & \\
\hline Left main disease & $226(0.5)$ & $14(0.7)$ & \\
\hline $\mathrm{PCl}$ & $42540(55.7)$ & $1837(37.7)$ & $<0.001$ \\
\hline Stented & 40662 (53.3) & 1746 (35.9) & $<0.001$ \\
\hline CABG & $2211(2.9)$ & $120(2.5)$ & 0.081 \\
\hline \multicolumn{4}{|l|}{ Complications } \\
\hline Prehospital CPR & $1129(1.6)$ & $48(1.2)$ & 0.040 \\
\hline Cardiogenic shock & $1990(2.7)$ & $135(2.8)$ & 0.717 \\
\hline Defibrillated VT/VF & $1903(2.5)$ & $110(2.3)$ & 0.285 \\
\hline Rupture & $107(0.1)$ & $6(0.1)$ & 0.097 \\
\hline Reinfarction during hospital stay & $956(1.3)$ & $67(1.4)$ & 0.422 \\
\hline CPAP usage & $3700(4.8)$ & $477(9.8)$ & $<0.001$ \\
\hline Bleeding causing surgery/transfusion & $1233(1.6)$ & $117(2.4)$ & 0.001 \\
\hline AV block II/III & $1424(1.9)$ & $94(1.9)$ & 0.160 \\
\hline Permanent pacemaker & $735(1.0)$ & $52(1.1)$ & 0.344 \\
\hline New onset atrial fibrillation & $3462(4.6)$ & 249 (5.2) & 0.107 \\
\hline Discharged with flutter/fibrillation & $4519(6.3)$ & 417 (9.3) & $<0.001$ \\
\hline LVEF at discharge & & & $<0.001$ \\
\hline Normal LVEF $\geq 50 \%$ & $28988(53.8)$ & $1422(45.0)$ & \\
\hline LVEF $40-49 \%$ & $12338(22.9)$ & $770(24.3)$ & \\
\hline LVEF $30-39 \%$ & $7748(14.4)$ & $545(17.2)$ & \\
\hline LVEF $<30 \%$ & $3809(7.1)$ & $342(10.8)$ & \\
\hline \multicolumn{4}{|l|}{ Discharge medications } \\
\hline ACE inhibitor & $42350(55.5)$ & $2460(50.6)$ & $<0.001$ \\
\hline Angiotensin II blocker & $8276(11.1)$ & $602(12.6)$ & 0.001 \\
\hline Aspirin & $68693(90.1)$ & $4158(85.5)$ & $<0.001$ \\
\hline Other platelet inhibitor & & & $<0.001$ \\
\hline Clopidogrel & $54439(71.4)$ & $3003(61.8)$ & \\
\hline Prasugrel & $331(0.4)$ & $9(0.2)$ & \\
\hline Other & $341(0.4)$ & $23(0.5)$ & \\
\hline$\beta$-blocker & $65675(86.1)$ & $3778(77.7)$ & $<0.001$ \\
\hline Statin & 60387 (79.2) & $3323(68.4)$ & $<0.001$ \\
\hline
\end{tabular}


Table 3 Continued

\begin{tabular}{lccc}
\hline & Non-COPD & COPD & p Value \\
\hline Calcium channel blocker & $9530(12.5)$ & $735(15.1)$ & $<0.001$ \\
Digoxin & $2309(3.0)$ & $294(6.0)$ & $<0.001$ \\
Diuretic & $22910(30.0)$ & $2397(49.3)$ & $<0.001$ \\
Nitrate & $9736(12.8)$ & $878(18.1)$ & $<0.001$ \\
Warfarin & $4039(5.3)$ & $314(6.5)$ & 0.008 \\
\hline
\end{tabular}

The count and percentage are presented for all categorical variables.

$\mathrm{AV}$, atrioventricular; CABG, coronary arterial bypass graft surgery; COPD, chronic obstructive pulmonary disease; CPAP, continuous positive airway pressure; CPR, cardiopulmonary resuscitation; LVEF, left ventricular ejection fraction; NSTEMI, non-ST-segment elevation myocardial infarction; PCI, percutaneous coronary intervention; STEMI, ST-segment elevation myocardial infarction; VF, ventricular fibrillation; VT, ventricular tachycardia.

\section{DISCUSSION}

Currently, there is limited knowledge about the effect of concomitant COPD on patients with MI regarding mortality and other cardiovascular events, especially in patients with contemporary treatment including PCI, dual antiplatelet therapy and statins. Our nationwide and contemporary study has a large patient population and reflects the present MI care in Sweden well. Thus, it provides new information to the field of patients with MI with a concurrent COPD diagnosis.

\section{Patient characteristics}

In our study, $6 \%$ of the study population had a COPD hospital discharge diagnosis, lower than the estimated prevalence of COPD in the general population (9-10\%), a finding in accordance with the previously reported problems of underdiagnosis. ${ }^{3}$ The increased age in the COPD group probably reflects that COPD is a late effect

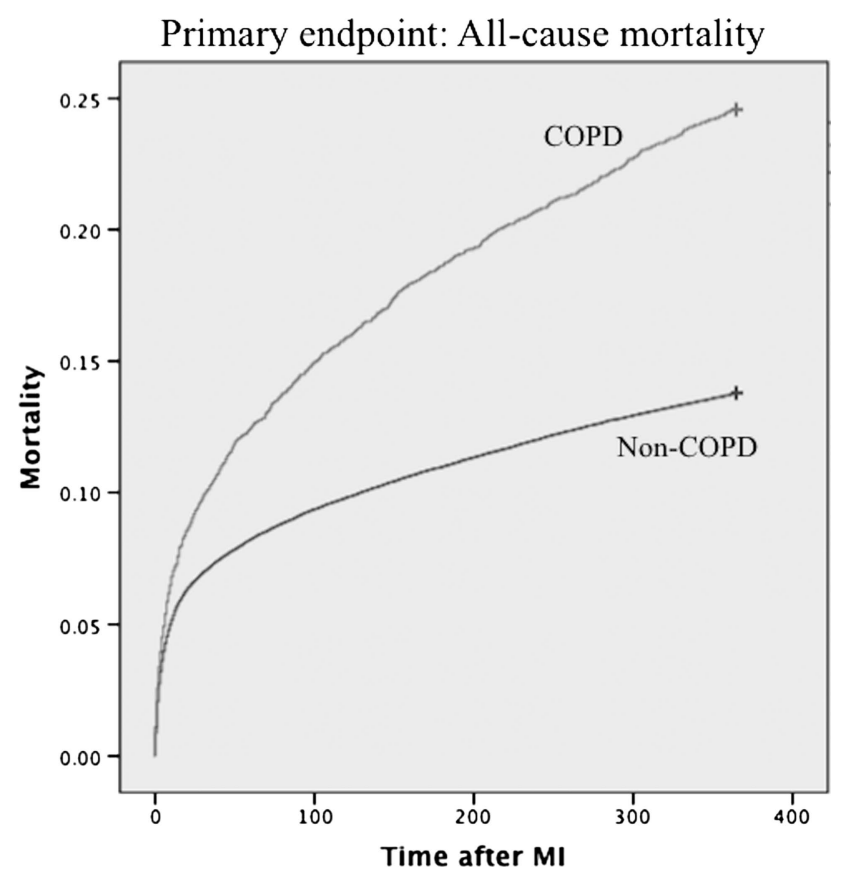

Figure 1 A Kaplan-Meier plot showing the crude 1-year mortality for patients with chronic obstructive pulmonary disease (COPD) versus patients without COPD. of lifelong smoking, but it could also be explained by underdiagnosis since COPD is relatively silent in early stages, and therefore the diagnosis does not surface until the manifestations are severe. As table 1 outlines, many of these patients also have previous cardiovascular events, in part due to a heavy smoking history but perhaps also due to reduced lung function and chronic inflammation of the lungs.

With regard to baseline characteristics and clinical presentation, several findings in our study are supported by previous studies. We found that patients with COPD had a larger burden of comorbidity and more atypical MI symptoms at presentation, in accordance with the findings of a previous study. ${ }^{20}$ However, we did not observe any differences in time delays from symptom onset to PCI or to the emergency room, as previously reported. ${ }^{20}$ Our data also did not support a previous study showing higher rates of cardiogenic shock in patients with COPD. ${ }^{27}$

\section{Treatments}

After an MI, many patients with COPD have previously not been prescribed $\beta$-blockers ${ }^{28}$ because clinicians fear that $\beta$-blockers will provoke bronchospasm and induce respiratory failure, even though cardioselective $\beta$-blockers have been proven to be safe and should not be routinely withheld from patients with COPD. ${ }^{29}$ Other types of standard post-MI treatment such as aspirin may also be used less often. ${ }^{22}$

As table 3 outlines, our findings are in line with these previous studies and show that standard post-MI treatment is withheld from patients with COPD more often than patients without COPD, especially with respect to $\beta$-blockers and surprisingly also statins which previously in observational studies have shown a dual cardiopulmonary protective effect. ${ }^{30}$ A systematic review including nine previous studies suggests that statins may also have a beneficial role in the treatment of COPD in itself. ${ }^{31}$

\section{Outcomes}

Previous studies have reported conflicting findings. Bursi et $a l^{21}$ reported a worse 5-year survival rate in patients with COPD (46\%) compared to those without COPD $(68 \%)$, and the association between COPD and 
Table 4 Clinical endpoints for patients with COPD as compared to patients without COPD at 1 year

\begin{tabular}{|c|c|c|c|}
\hline & Crude HR (95\% Cl) & Adjusted† HR (95\% Cl) & Adjustedł HR $(95 \% \mathrm{Cl})$ \\
\hline All-cause mortality & $1.86(1.76 \text { to } 1.98)^{\star \star \star}$ & $1.32(1.24 \text { to } 1.40)^{\star \star \star}$ & $1.14(1.07 \text { to } 1.21)^{\star \star \star}$ \\
\hline Reinfarction & $1.17(1.09 \text { to } 1.26)^{\star \star \star}$ & $1.00(0.93$ to 1.08$)$ & $0.99(0.92$ to 1.06$)$ \\
\hline New-onset stroke & $1.14(0.93$ to 1.40$)$ & 0.90 (0.73 to 1.12$)$ & $0.89(0.72$ to 1.11$)$ \\
\hline New-onset bleeding & $1.45(1.25 \text { to } 1.69)^{\star * *}$ & $1.13(0.96$ to 1.32$)$ & $1.12(0.96$ to 1.31$)$ \\
\hline New-onset heart failure & $1.84(1.70 \text { to } 1.99)^{\star \star \star}$ & $1.46(1.34 \text { to } 1.58)^{\star \star \star}$ & $1.35(1.24 \text { to } 1.47)^{\star \star \star}$ \\
\hline
\end{tabular}

death was independent of age and risk factors (HR 1.30, $95 \%$ CI 1.10 to 1.54$)$. In another study by Salisbury et $a l^{22}$, patients with COPD had a twofold higher 1-year mortality rate after adjustment for baseline differences (HR 2.00, $95 \%$ CI 1.44 to 2.79 ) and higher rehospitalisation rates (HR 1.22, 95\% CI 1.01 to 1.48 ). On the other hand, the older study by Behar $e t a l^{2}$ did not find an independent association between COPD and a higher risk of early death or long-term mortality among survivors of acute MI

Our study showed that patients with a prior COPD hospital discharge diagnosis had a considerably higher crude 1-year mortality after an MI (HR 1.86, 95\% CI 1.76 to 1.98) compared to patients without COPD with an MI. However, we could show that this association was greatly lowered after adjusting for baseline characteristics and comorbidities (HR 1.32, 95\% CI 1.24 to 1.40 ) and, perhaps most importantly, after also adjusting for different treatment patterns, only a modest increase in adjusted mortality remained (HR 1.14, 95\% CI 1.07 to 1.21).

Therefore, our results indicate that patients with COPD with an MI constitute a very high risk group with a nearly doubled unadjusted mortality rate compared to patients without COPD with an MI and that the excess mortality could perhaps be lowered with more aggressive evidence-based treatments for both the MI as well as concomitant diseases. However, our results are only suggestive and it would require a prospective, interventional study to confirm our findings. COPD was not independently associated with a higher 1-year re-admission for reinfarction, new-onset stroke or new-onset bleeding rate but was independently associated with an increased newonset heart failure rate.

The observed association between a prior COPD diagnosis before MI and a higher frequency of subsequent new onset of heart failure even after multivariate adjustment raises several questions. Not much is known about the association of heart failure and COPD. Previous authors have suggested a common inflammatory background between the conditions. ${ }^{33}$ The actual prevalence of decreased left ventricular function in patients with COPD is largely unknown and clinically poorly defined. $^{33} 34$ Shared signs, symptoms and pulmonary function test findings between heart failure and COPD further complicate the relationship. Patients with COPD may suffer from pulmonary hypertension, ${ }^{35}$ which could lead to right ventricular dysfunction, ${ }^{36}$ and because of a similar symptomatology between cor pulmonale and true left ventricular failure, it is hard to discern and distinguish the exact aetiology of the heart failure diagnosis. Dyspnoea and exercise intolerance are cardinal symptoms for COPD and heart failure resulting in diagnostic difficulties, and misclassification in the National Patient Registry cannot be ruled out. However, in the present study, patients with COPD did have a higher rate of decreased left ventricular ejection fraction at discharge and they were also undertreated post-MI with guideline recommended secondary prevention medications. This could lead to a higher frequency of newonset heart failure.

\section{Limitations}

Our study design was observational, and thus a certain degree of residual confounding cannot be ruled out. Since COPD is an underdiagnosed disease, ${ }^{45}$ a number of patients in the non-COPD group could have met the criteria for COPD if they had been thoroughly investigated with spirometry, an inherent limitation of any retrospective COPD study. ${ }^{37}$ The underdiagnosis of COPD could potentially result in an under-representation in the registry that could underestimate our findings. Furthermore, we did not have optimal data regarding the patients' smoking history, as pack-years, date of smoking cessation and information about smoking post-MI were lacking. We also did not have information on pulmonary function testing, such as FEV1/forced vital capacity ratios, and therefore the severity of COPD diagnoses cannot be evaluated in our patient population. Moreover, a wide range of physicians has diagnosed the COPD cases, and thus the criteria for COPD may differ between patients in the population. The same problem is applicable to the heart failure diagnoses. However, the validity of COPD and heart failure diagnoses in national Swedish registers has recently been reported to be good. ${ }^{25} 38$

\section{CONCLUSIONS}

The main finding in this nationwide study of patients with MI with contemporary treatment including dual antiplatelet treatment and PCI was that a COPD 
diagnosis at baseline was associated with a high 1-year mortality. However, after multivariate adjustment for comorbidities and different treatment patterns, the residual increase in mortality was only modest (HR 1.14, 95\% CI 1.07 to 1.21 ). There was also an independent association between a COPD diagnosis and re-admission for new-onset heart failure. The mechanisms behind these associations are not clear. However, our findings suggest that improved cardiac treatment in patients with MI with COPD according to current guidelines could potentially result in improved survival.

Acknowledgements The authors would like to thank the staff members in all coronary care units in Sweden for their help and cooperation in contributing data to the Swedish Web-system for Enhancement and Development of Evidence-based care in Heart disease Evaluated According to Recommended Therapies (SWEDEHEART) system.

Contributors All authors fulfil all three of the guidelines for authorship. (1) Substantial contributions to conception and design, acquisition of data or analysis and interpretation of data; (2) drafting the article or revising it critically for important intellectual content and (3) final approval of the version to be published.

Funding This study has been funded by research grants from the Swedish Foundation of Strategic Research (http://www.stratresearch.com/en/). The SWEDEHEART registry is publicly funded by the Swedish state and regional authorities.

\section{Competing interests None.}

Data sharing statement No additional data are available.

Open Access This is an Open Access article distributed in accordance with the Creative Commons Attribution Non Commercial (CC BY-NC 3.0) license, which permits others to distribute, remix, adapt, build upon this work noncommercially, and license their derivative works on different terms, provided the original work is properly cited and the use is non-commercial. See: http:// creativecommons.org/licenses/by-nc/3.0/

\section{REFERENCES}

1. WHO. World Health Statistics. 2008. http://www.who.int/whosis/ whostat/EN WHS08 Full.pdf

2. Mackay J, Eriksen M. WHO atlas maps global tobacco epidemic. Public Health Rep 2002;117:479.

3. Halbert RJ, Natoli JL, Gano A, et al. Global burden of COPD: systematic review and meta-analysis. Eur Respir J 2006;28:523-32.

4. Lindstrom $\mathrm{M}$, Jonsson $\mathrm{E}$, Larsson $\mathrm{K}$, et al. Underdiagnosis of chronic obstructive pulmonary disease in Northern Sweden. Int J Tuberc Lung Dis 2002;6:76-84.

5. Pena VS, Miravitlles M, Gabriel R, et al. Geographic variations in prevalence and underdiagnosis of COPD: results of the IBERPOC multicentre epidemiological study. Chest 2000;118:981-9.

6. Make B, Dutro MP, Paulose-Ram R, et al. Undertreatment of COPD: a retrospective analysis of US managed care and medicare patients. Int J Chron Obstruct Pulmon Dis 2012;7:1-9.

7. Bednarek M, Maciejewski J, Wozniak M, et al. Prevalence, severity and underdiagnosis of COPD in the primary care setting. Thorax 2008;63:402-7.

8. Doll $\mathrm{R}$, Peto $\mathrm{R}$, Wheatley $\mathrm{K}$, et al. Mortality in relation to smoking: 40 years' observations on male British doctors. BMJ 1994;309:901-11.

9. Rabe KF. Treating COPD-the TORCH trial, $\mathrm{P}$ values, and the Dodo. N Engl J Med 2007;356:851-4.

10. Anthonisen NR, Connett JE, Kiley JP, et al. Effects of smoking intervention and the use of an inhaled anticholinergic bronchodilator on the rate of decline of FEV1. The Lung Health Study. JAMA 1994;272:1497-505.

11. Lofdahl CG. COPD and co-morbidities, with special emphasis on cardiovascular conditions. Clin Respir J 2008;2(Suppl 1):59-63.

12. Calverley PM, Anderson JA, Celli B, et al. Salmeterol and fluticasone propionate and survival in chronic obstructive pulmonary disease. N Engl J Med 2007;356:775-89.
13. Sin DD, Wu L, Man SF. The relationship between reduced lung function and cardiovascular mortality: a population-based study and a systematic review of the literature. Chest 2005;127:1952-9.

14. Engstrom G, Wollmer P, Hedblad B, et al. Occurrence and prognostic significance of ventricular arrhythmia is related to pulmonary function: a study from 'men born in 1914,' Malmo, Sweden. Circulation 2001;103:3086-91.

15. Mannino DM, Watt G, Hole D, et al. The natural history of chronic obstructive pulmonary disease. Eur Respir J 2006;27:627-43.

16. Hole DJ, Watt GC, Davey-Smith G, et al. Impaired lung function and mortality risk in men and women: findings from the Renfrew and Paisley prospective population study. BMJ 1996;313:711-15; discussion 5-6.

17. Calverley PM, Scott S. Is airway inflammation in chronic obstructive pulmonary disease (COPD) a risk factor for cardiovascular events? COPD 2006;3:233-42.

18. Engstrom G, Lindberg C, Gerhardsson de Verdier M, et al. Blood biomarkers and measures of pulmonary function-a study from the Swedish twin registry. Respir Med 2012;106:1250-7.

19. McAllister DA, Maclay JD, Mills NL, et al. Arterial stiffness is independently associated with emphysema severity in patients with chronic obstructive pulmonary disease. Am J Respir Crit Care Med 2007:176:1208-14.

20. Hadi HA, Zubaid M, Al Mahmeed W, et al. Prevalence and prognosis of chronic obstructive pulmonary disease among 8167 Middle Eastern patients with acute coronary syndrome. Clin Cardiol 2010;33:228-35.

21. Bursi F, Vassallo R, Weston SA, et al. Chronic obstructive pulmonary disease after myocardial infarction in the community. Am Heart J 2010;160:95-101.

22. Salisbury AC, Reid KJ, Spertus JA. Impact of chronic obstructive pulmonary disease on post-myocardial infarction outcomes. $\mathrm{Am} \mathrm{J}$ Cardiol 2007; 99:636-41.

23. Jernberg T, Attebring MF, Hambraeus K, et al. The Swedish Web-system for enhancement and development of evidence-based care in heart disease evaluated according to recommended therapies (SWEDEHEART). Heart 2010;96:1617-21.

24. Swedish National Board of Health and Welfare. Swedish National Patient Register. http://www.socialstyrelsen.se/register/ halsodataregister/patientregistret/inenglish

25. Inghammar M, Engstrom G, Lofdahl CG, et al. Validation of a COPD diagnosis from the Swedish Inpatient Registry. Scand J Public Health 2012;40:773-6.

26. Textor J, Hardt J, Knuppel S. DAGitty: a graphical tool for analyzing causal diagrams. Epidemiology 2011;22:745.

27. Wakabayashi K, Gonzalez MA, Delhaye C, et al. Impact of chronic obstructive pulmonary disease on acute-phase outcome of myocardial infarction. Am J Cardiol 2010;106:305-9.

28. Egred M, Shaw S, Mohammad B, et al. Under-use of beta-blockers in patients with ischaemic heart disease and concomitant chronic obstructive pulmonary disease. QJM 2005;98:493-7.

29. Salpeter $\mathrm{S}$, Ormiston T, Salpeter E. Cardioselective beta-blockers for chronic obstructive pulmonary disease. Cochrane Database Syst Rev 2005;(4):CD003566.

30. Mancini GB, Etminan M, Zhang B, et al. Reduction of morbidity and mortality by statins, angiotensin-converting enzyme inhibitors, and angiotensin receptor blockers in patients with chronic obstructive pulmonary disease. J Am Coll Cardiol 2006;47:2554-60.

31. Janda S, Park K, FitzGerald JM, et al. Statins in COPD: a systematic review. Chest 2009;136:734-43.

32. Behar S, Panosh A, Reicher-Reiss $\mathrm{H}$, et al. Prevalence and prognosis of chronic obstructive pulmonary disease among 5,839 consecutive patients with acute myocardial infarction. SPRINT Study Group. Am J Med 1992;93:637-41.

33. Barnes PJ, Celli BR. Systemic manifestations and comorbidities of COPD. Eur Respir J 2009;33:1165-85.

34. Rutten FH, Cramer MJ, Lammers JW, et al. Heart failure and chronic obstructive pulmonary disease: an ignored combination? Eur $\mathrm{J}$ Heart Fail 2006;8:706-11.

35. Barbera JA, Peinado VI, Santos S. Pulmonary hypertension in chronic obstructive pulmonary disease. Eur Respir J 2003:21:892-905.

36. Vizza CD, Lynch JP, Ochoa LL, et al. Right and left ventricular dysfunction in patients with severe pulmonary disease. Chest 1998:113:576-83

37. Damarla M, Celli BR, Mullerova HX, et al. Discrepancy in the use of confirmatory tests in patients hospitalized with the diagnosis of chronic obstructive pulmonary disease or congestive heart failure. Respir Care 2006;51:1120-4.

38. Ingelsson $\mathrm{E}$, Arnlov J, Sundstrom J, et al. The validity of a diagnosis of heart failure in a hospital discharge register. Eur $J$ Heart Fail 2005;7:787-91. 